\title{
Rescheduling a three shift system at a steel rolling mill: effects of a one hour delay of shift starting times on sleep and alertness in younger and older workers
}

\author{
Roger R Rosa, Mikko Härmä, Katriina Pulli, Mirjam Mulder, Ove Näsman
}

\begin{abstract}
Objective-To evaluate a new work schedule at a Finnish steel mill with special attention to effects on older workers. The schedule was designed to improve sleep before the morning shift, and alertness during the morning shift, by delaying shift start and end times.
\end{abstract}

Methods-Evaluation was by a shiftwork health and safety questionnaire, recordings of work-rest-sleep cycles with activity monitors worn on the wrist, daily diaries, and on site computerised testing of fatigue and alertness by the NIOSH fatigue test battery.

Results-The one hour delay in shift starting times improved sleep before the morning shift, and improved waking fatigue, sleepiness, and performance during the morning shift. Evening and night shift sleep and fatigue or sleepiness, however, were affected negatively by the new work schedule, but the results for those shifts were less consistent across the various measures. Despite the improvements, most workers were not satisfied with the new schedule because of social concerns. Few interactions of age with the new work schedule were found, suggesting that the effects of the work schedule were uniform across age groups.

Conclusion-A change of as little as one hour in shift starting times can improve morning shift sleep and alertness, but there are trade offs from these improvements in terms of night shift effects and social considerations. It seems, then, that optimal shift start and end times for an entire organisation are difficult to institute on a wide scale. Tailoring shift schedules to subgroups within an organisation is suggested.

(Occup Environ Med 1996;53:677-685)

Keywords: shift timing; shiftworker; sleep; fatigue

Studies examining various shift schedules suggest that they can be designed systematically to improve sleep, alertness, and fatigue, and techniques for designing such schedules have been proposed. ${ }^{12}$ These alternative shift systems point to several variables which could be changed when redesigning a schedule. One important variable affecting sleep, for example, is the start and end times of the shift, which dictate the time allowed for sleep. ${ }^{34}$ Questionnaire studies have suggested that morning shifts should not start very early because early starts can truncate sleep taken before that shift, and also increase self perceived sleepiness and fatigue during the subsequent waking hours. ${ }^{15-9}$ In a three shift system in 24 hours, however, delayed start and end times for morning shifts necessarily result in delayed start and end times for evening and night shifts. A later ending time for the night shift can curtail daytime sleep. Worksite studies have shown that sleep duration decreased when sleep onset was delayed after the night shift. ${ }^{510}$ Bjerner et $a l,{ }^{5}$ for example, reported that when the shift change time was delayed from 0400 to 0600 hours, sleep duration after the night shift decreased from 5.75 hours to 5 hours, but sleep before the morning shift increased from 6 to 6.75 hours. Consistent with these studies, laboratory studies of circadian influences on sleep have shown that sleep duration depends directly on the time of sleep onset, with duration being shortest for sleep starting during daylight hours. ${ }^{112}$ Taken together, these studies raise the question of how to optimise shift start and end times to give adequate sleep before the morning shift, or after the night shift, and maintain waking alertness at reasonable levels during those shifts. The selection of which shift to favour in such cases may depend on the job demands of the particular shift. For example, if the most difficult work occurs during the morning shift, then shift start and end times could be adjusted to maximise alertness for that shift.

Individual factors, such as age, also might influence the selection of start and end times. A frequently observed feature of aging is a tendency toward "morningness", or a preference for earlier wake up and retiring times compared with younger people. ${ }^{1314}$ As well as being morning types, older people also report poorer sleep quality than younger people, and electroencephalographic measurement of sleep has verified these reports by showing age related increases in stage 1 (light) sleep, combined with more frequent awakenings from sleep. ${ }^{15}$ Furthermore, increased disturbances in shiftworkers' sleep have been associated with age. ${ }^{16-19}$ Foret et $a l,{ }^{16}$ for example, reported a negative association between duration of shiftwork service (which is correlated 
with age) and subjective sleep quality. Other studies have shown that middle aged and older shiftworkers sleep less well than younger workers, especially during day sleep after night work. ${ }^{15}$ 17-19

Selection of start and end times, then, might depend not only on job demands, but also on the age distribution of the workforce. There are no systematic studies, however, assessing the effect of different shift starting and ending times on sleep and alertness in older shiftworkers. Furthermore, no attempts have been made to improve the sleep and alertness in these workers through the design of new work schedules.

The present study evaluated the impact of a one hour delay in the start and end times of a rotating shift schedule on sleep, alertness, and performance of workers at a steel rolling mill. Particular attention was given to the effects of the intervention on older workers

\section{Methods}

SELECTION OF WORK SCHEDULE

The new work schedule (fig 1) was chosen by worker vote from several schedules suggested to improve sleep and fatigue in older workers. The proposed schedules were based partly on a preliminary questionnaire (the standard shiftwork index $)^{20}$ at the factory which indicated that night time sleep before the morning shift was as brief as daytime sleep after the night shift (initial test, fig 2). Also, questionnaire ratings of fatigue during the morning shift at that site were as high as those given for the night shift (initial test, fig 3). These results contrasted with responses from a second steel factory which had shift starting times delayed by one hour. Morning shift sleep at the second factory lasted considerably longer than night shift sleep and morning fatigue ratings, especially from older workers, were lower than night ratings. From these results it was hypothesised that a delay in starting times might improve morning shift sleep and fatigue. Consequently, work schedules were proposed which included delayed starting times.

\section{DESIGN}

The new shift schedule was evaluated by questionnaire given to all factory workers, and by extensive measurement of home sleep and worksite performance and alertness in a smaller group of workers. Baseline testing was accomplished four to six months before the establishment of the new schedule (March-
May), and follow up testing occurred at the end of a four month trial period under the new schedule (November-March). For comparison, the same tests were given twice at the same times of year at a second factory, where no change of schedule occurred.

\section{WORKSITES}

The two factories participating in the evaluation were from the same corporation and located in the same geographical area. Environmental conditions at each plant were similar in that they were dark and dusty, with a high level of noise, and with the potential for exposure to large variations in temperature. The new shift schedule was established at site 1 , which was a rolling mill where steel billets were processed into wire. Site 2 , where no change of schedule occurred, was an ore processing mill which produced steel billets. Most of the work at both sites was automated, requiring workers to monitor processes and operate self propelled machinery, but there were also operations which required heavy physical labour from some workers.

\section{WORK SCHEDULES}

Figure 1 shows the original work schedules used at each site. At both factories, a rotating three shift schedule was used, consisting of morning, evening, and night shifts, followed by free days. The original starting and ending times for the shifts at site 1 were one hour earlier than at site 2 . During the new schedule, all start and end times at site 1 were delayed by one hour. The later start and end times were in effect throughout the study at site 2 . Figure 1 shows that the direction of shift rotation, number of consecutive days per shift, and number of free days differed at each site. Consequently, site 2 cannot be considered a precise statistical control for the intervention at site 1 .

\section{SUBJECTS}

Age effects were examined by arbitrarily selecting age 40 to divide workers into younger and older groups. Table 1 shows demographic characteristics of the questionnaire respondents, and of the smaller group who participated in the sleep diary, actigraph, and performance and alertness tests. Workers in the smaller group volunteered their participation on a first come, first served basis. Time and equipment limitations precluded extensive measurement of all subjects who participated in the questionnaire survey.

Questionnaires were distributed to all shift-
Figure 1 Shift schedules for typical crews at each worksite. The change in the work schedule occurred at site 1 . Shifts are labelled $E=$ evening $M=$ morning, $N=$ nights, and $R=$ at least $24 h$ rest

Site 1
Start-end times
Site 2
Start-end times

\section{EEEE R}

$1400-2200$

M M M R

0700-1500
M M M M R

N N N N

0600-1400

$2200-0600$

EEE R

N N N

R R R 
Figure 2 Standard shiftwork index, sleep diary, and actigraph estimates of total sleep time as a function of test phase for each shift at sites 1 and 2. Error bars are SDs. The Newman-Keuls test showed significant differences.

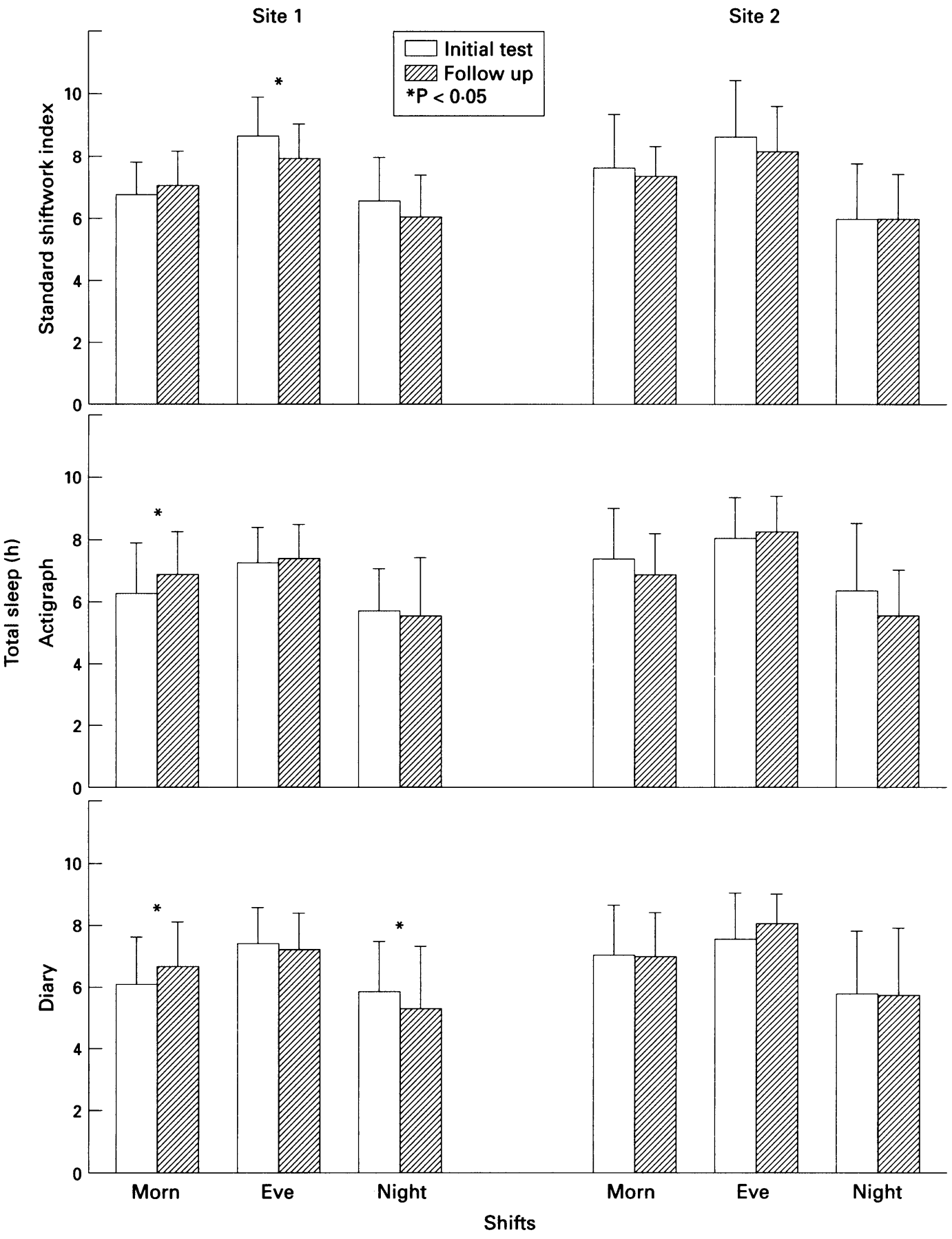

workers at each site. Response rate was $88 \%$ at site 1 and $64 \%$ at site 2 . Table 1 shows that a similar number of younger and older workers participated in the questionnaire evaluation at site 1 , but not at site 2 . It is also evident from table 1 that the characteristics of the smaller group of diary/actigraph/alertness test respondents at each site were similar to those of the larger group, except in the percentage of parents with young children and in the greater number of older subjects at site 2 . Also, examination of sleep duration by the standard shiftwork index suggested little difference between the smaller and larger groups. On the basis of these similarities, it was assumed that the smaller group of respondents was reasonably representative of the larger group at each site. Consequently, inferences about daily sleep and alertness in these groups were assumed to be representative of all workers at each site. 
Figure 3 Standard shiftwork index ratings of tiredness and visual analogue scale ratings of sleepiness as a function of test phase for each shift at site 1 and site 2. Error bars are SDs. The NewmanKeuls test showed significant differences.
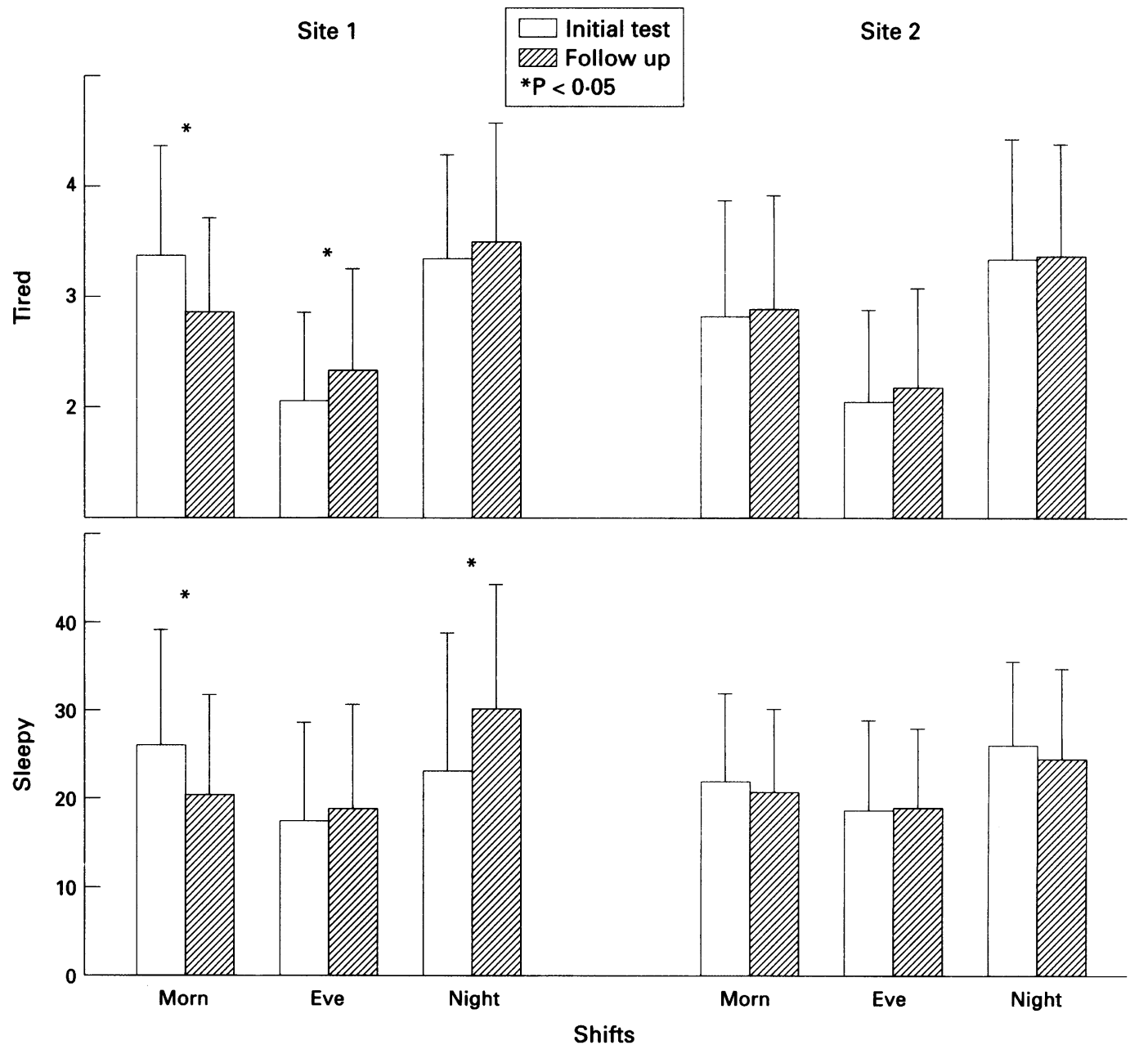

MEASUREMENTS

Evaluation of questionnaire

Items from the standard shiftwork index ${ }^{20}$ were examined for possible effects of age or change in shift associated with the new work schedule. Selected items included sleep duration per shift (morning, evening, or night shifts), which was calculated from the usual retiring and rising times reported for sleep immediately before, during, and immediately after each shift sequence. Also, various measures of sleep quality were rated on 1-5 scales for each shift and for free days. The sleep quality measures included: satisfaction with amount of sleep, quality of sleep, feeling of refreshment after sleep, frequency of waking too early from sleep, frequency of problems falling asleep, use of sleeping pills, use of alcohol to induce sleep, and feelings of fatigue during the work shift. Other variables examined from the standard shiftwork index included: ratings of chronic fatigue, "morningness" or "eveningness" type, physical and mental workload during each shift, health complaints, job satisfaction, and the degree of interference of the shift schedule with domestic activities, leisure activities, and other (non-specific) activities.

Evaluation of daily sleep and performance and alertness

General test schedule-For each worker, home sleep, performance, and alertness were measured simultaneously for about one shift cycle.
Individual participation times ranged from 12-18 days at site 1 and 10-20 days at site 2 .

Sleep diary-A printed booklet was given to each worker for recording multiple sleep periods each day in a standard format requiring entries before and after each sleep period. The questions and scales included in the diary were developed and used successfully in previous studies. ${ }^{21-24}$ Before each sleep period, the worker recorded the bed time and noted the use of sleep aids (including alcohol and sleep medications) and health complaints. After each sleep period, the worker recorded the rising time, estimated minutes to falling asleep (sleep latency), number of awakenings, and minutes awake during the sleep period. The worker also rated the quality of sleep and the feeling of refreshment on awakening on nine point scales, and the feeling of awakening too early from sleep on a five point scale, and noted any unusual events which might affect sleep. Diary entries were made for at least one shift cycle.

Activity monitor-Daily rest and activity cycles were monitored with an "actigraph" recording unit (Ambulatory Monitoring, Ardsley, New York) worn on the wrist which converts movement into an electronic signal that is stored in digital memory. The worker was instructed to wear the actigraph continuously for a complete shift cycle, except during bathing and during work time (to avoid exposing the actigraph to extreme temperature variations). On retiring, the worker was instructed 
to press a button on the actigraph to signal the event, and to press the button again on arising. These signals were verified by comparison with sleep diary entries. Data from the actigraph were scored for sleep with validated algorithms provided in the manufacturer's software. Sleep variables analysed in the present study included: time in bed, total time asleep, sleep latency, and frequency of awakenings.

Performance and alertness-Tests of on site performance and alertness were selected from the NIOSH fatigue test battery, which has been described in detail in previous reports, ${ }^{25} 26$ and used successfully in previous worksite studies. ${ }^{21}{ }^{23}$ As in previous studies, management would permit access to the worksite only if testing minimally interfered with the workers' job responsibilities. Therefore, test sessions were limited to about 15 minutes. The performance test selected for the present study was 10 minutes (125 trials) of unprepared two choice reaction time which is sensitive to changes in alertness associated with sleep or hours of work. The reaction time task was scored for mean response time, percentage of choice errors, and percentage of misses (failure to respond within 1.5 seconds).

As well as performance, subjective sleepiness was assessed on the computer with a 50 point visual analogue rating scale measured twice during each test session. Also, self reported physical and mental workloads for a particular shift were rated on seven point numerical scales only during the final test session of the shift.

Personal computers for presenting the tests were distributed at each worksite in accessible locations secluded from the noise, heat, and other activities of the manufacturing process. The computers controlled the instructions for, and presentation of, the reaction time task, and the self reported scales. A brief introduction to the purpose of the study, the computers, and the tests was the only intervention by the experimenter before testing began. Except for a brief training session, the experimenters were not present during data collection. To initiate the test session, the subject sat at the computer console and typed a simple command.

The workers were instructed to complete the tests during the first and last hour of both the first and the final workday of each shift (morning, evening, and night). Job demands sometimes interfered with this schedule, however, which resulted in variable participation rates among the workers.

\section{DATA ANALYSES}

Because of differences in the work schedules and an unmanageable number of complex interactions, data from each worksite were first analysed separately. Follow up analyses combining data from both worksites were then performed to examine overall effects of age, and to verify other main effects and simple interactions.

Before analysis, several dependent variables were transformed to approximate to a normal distribution. ${ }^{27}$ Sleep latency estimates from the diary and the actigraph were transformed to logarithms, reaction times were transformed to their inverses, and percentage scores (choice reaction time errors and reaction time signal misses) were transformed to the arcsine of their square roots. The standard shiftwork index measure of sleep duration, and all sleep diary and actigraph variables, were analysed with separate analysis of varience (ANOVAs) that had terms for age group (older $v$ younger), test phase (initial test $v$ follow up), shift (morning, evening, night), day within the shift sequence (before the first shift, between shifts, after the last shift), and their interactions. For these ANOVAs, age group was a factor between subjects, and test phase, shift, and day were repeated measures factors.

Standard shiftwork index variables of sleep quality and workload ratings were examined through ANOVA with age group as the between subjects factor, and test phase and shift (morning, evening, night, free day) as repeated measures factors. Standard shiftwork index measures of chronic fatigue, morningness, health complaints, job satisfaction, and the degree of interference of the shift schedule with domestic activities, leisure activities, and other (non-specific) activities also were examined with separate ANOVAs with terms for age group, test phase, and their interaction. The SAS General Linear Models Procedure ${ }^{28}$ was used to calculate multivariate solutions for all ANOVAs of the variables of the standard shiftwork index, diary, and actigraph. Differences between means for all significant effects were examined further with the Newman-Keuls test.

Worksite measures of performance and alertness were analysed with ANOVAs that had terms for age group (older $v$ younger), test phase (initial test $v$ follow up), shift (morning, evening, night), time on shift (early $v$ late), consecutive workday, and their interactions. For these ANOVAs, age group was a between subject factor, and test phase, workday, shift, and time on shift were repeated measures factors. Instead of the usual least squares solution, maximum likelihood solutions to these ANOVAs were calculated with the SAS mixed procedure. ${ }^{29}$ This procedure was selected because of its computational efficiency for analysing data from complicated, unbalanced designs, and because it allows specification of an autoregressive covariance structure in the error term. Specification of such a structure was desirable to control for possible learning or carryover effects. Differences between means for all significant effects were examined further with the Newman-Keuls test.

\section{Results}

SLEEP QUANTITY AND QUALITY

Sleep quantity

Figure 2 shows the standard shiftwork index, actigraph, and sleep diary measures of total duration of sleep at each site for each shift at each test phase (before and after the schedule change at site 1 ). Figure 2 indicates that all 
Table 2 Total sleep time for each shift for the older and younger groups as measured by the standard shiftwork index, the actigraph, and the sleep diary

\begin{tabular}{|c|c|c|c|c|c|}
\hline & \multicolumn{3}{|l|}{ Shift } & \multirow[b]{2}{*}{$F$} & \multirow[b]{2}{*}{$P$} \\
\hline & $\begin{array}{l}\text { Morning } \\
\text { mean }(S D)\end{array}$ & $\begin{array}{l}\text { Evening } \\
\text { mean (SD) }\end{array}$ & $\begin{array}{l}\text { Night } \\
\text { mean (SD) }\end{array}$ & & \\
\hline \multicolumn{6}{|l|}{ SSI: } \\
\hline $\begin{array}{l}\text { Younger }(n=83) \\
\text { Older }(n=125)\end{array}$ & $\begin{array}{l}7.14(1.01) \\
7.53(1.49)\end{array}$ & $\begin{array}{l}8 \cdot 89(1 \cdot 25) \\
8 \cdot 23^{\star}(1 \cdot 33)\end{array}$ & $\begin{array}{l}6 \cdot 65(1 \cdot 20) \\
5 \cdot 77^{\star}(1 \cdot 56)\end{array}$ & $10 \cdot 37$ & 0.001 \\
\hline \multicolumn{6}{|l|}{ Actigraph: } \\
\hline $\begin{array}{l}\text { Younger }(n=20) \\
\text { Older }(n=25)\end{array}$ & $\begin{array}{l}6.76(1.64) \\
6.85(1.54)\end{array}$ & $\begin{array}{l}7.63(1.23) \\
7.52(1.26)\end{array}$ & $\begin{array}{l}6 \cdot 37(1 \cdot 80) \\
5 \cdot 18^{\star}(1 \cdot 93)\end{array}$ & $8 \cdot 20$ & 0.001 \\
\hline \multicolumn{6}{|l|}{ Diary: } \\
\hline $\begin{array}{l}\text { Younger }(n=20) \\
\text { Older }(n=25)\end{array}$ & $\begin{array}{l}6.55(1.63) \\
6.72(1.49)\end{array}$ & $\begin{array}{l}7 \cdot 50(1 \cdot 15) \\
7 \cdot 42(1 \cdot 40)\end{array}$ & $\begin{array}{l}6 \cdot 27(1 \cdot 95) \\
5 \cdot 15^{\star}(1 \cdot 82)\end{array}$ & $9 \cdot 66$ & 0.001 \\
\hline
\end{tabular}

$\star \mathrm{P}<0.05 v$ younger group (Newman-Keuls test).

Values represent both worksites combined. F values are from the interaction of age group with shift.

measures show an increase in total sleep for the morning shift after the change in schedule at site 1. Similar increases for morning shift did not occur at follow up testing at site 2 . For evening shift, figure 2 indicates that changes in total sleep from the first to second test phase were not consistent across measures at either worksite. For the night shift, standard shiftwork index and diary measures of total sleep at site 1 decreased after the schedule changed whereas the actigraph measure remained the same. For the night shift at site 2 , the standard shiftwork index and diary measures were the same at each test phase, but the actigraph measure showed a possible decrease at follow up testing.

Differences at each test phase for each shift at site 1 were supported by a significant interaction of test phase by shift for the standard shiftwork index $(\mathrm{df}=2,54, \quad \mathrm{~F}=11 \cdot 27$, $\mathrm{P}<0.001$ ), the diary ( $\mathrm{df}=2,25, \mathrm{~F}=4.71$, $\mathrm{P}<0.006)$, and the actigraph $(\mathrm{df}=2,20, \mathrm{~F}$ $=6.21, P<0.01)$ measures. No significant interactions of shift with test phase were found for site 2. Subsequent tests of means from site 1 showed a significant increase in both diary and actigraph measures of total sleep for the morning shift. For the evening shift, only the standard shiftwork index measure was significantly different from before to after the change. For the night shift, only the diary measure was significantly different from before to after the change.

No interactions between age group and test phase were found at either site for any measure of total sleep time. However, overall differences in total sleep were found between age groups as a function of shift. Table 2 shows the total sleep time for each shift, for the older and younger groups, along with the $F$ values for both worksites combined. Table 2 shows that the older workers obtained consistently less sleep in association with night shift, but morning shift sleep was similar for both age groups, regardless of type of measurement. Also, the older workers reported significantly less evening shift sleep as measured by the standard shiftwork index.

\section{Sleep quality}

Table 3 shows the means for select variables of the standard shiftwork index as a function of shift and test phase along with the $F$ values for the interaction of test phase with shift at each worksite. Table 3 shows that the change in schedule was associated with increased quality for two variables on the morning shift, but decreased quality for all variables on the evening and night shifts at site 1 . No differences between test phase as a function of age group or shift were found at site 2 .

The sleep diaries showed a significant main effect of test phase at site $1(\mathrm{df}=1,17, F=$ $6.52, P<0.03)$ reflecting an overall reduction in sleep quality ratings after the schedule change. This reduction was found for all shifts. These results are not consistent with morning shift results from the questionnaire, in which an increase in sleep quality was found after the schedule change. The results are consistent, however, with evening and night shift results from the questionnaire in which a decrease in sleep quality was found after the schedule change. No remarkable effects were found for diary reports of napping at the job site, health complaints, use of alcohol or sleeping medication, or occurrence unusual events. At site 2, changes in sleep quality as reported

Table 3 Standard shiftwork index ratings of sleep quality for each test phase at sites $1(n=68)$ and $2(n=140)$

\begin{tabular}{|c|c|c|c|c|c|c|}
\hline & \multicolumn{3}{|l|}{ Shift } & \multirow[b]{2}{*}{$\begin{array}{l}\text { Free day } \\
\text { mean }(S D)\end{array}$} & \multirow[b]{2}{*}{$F$} & \multirow[b]{2}{*}{$P$} \\
\hline & $\begin{array}{l}\text { Morning } \\
\text { mean }(S D)\end{array}$ & $\begin{array}{l}\text { Evening } \\
\text { mean }(S D)\end{array}$ & $\begin{array}{l}\text { Night } \\
\text { mean }(S D)\end{array}$ & & & \\
\hline \multicolumn{7}{|c|}{$\begin{array}{l}\text { Quality of sleep ( } 1=\text { very bad, } \\
5=\text { very good): } \\
\text { Site } 1 \text { : }\end{array}$} \\
\hline $\begin{array}{l}\text { Before change } \\
\text { After change }\end{array}$ & $\begin{array}{l}2.98(0.92) \\
3.09(0.74)\end{array}$ & $\begin{array}{l}3.68(0.71) \\
3.39^{\star}(0.88)\end{array}$ & $\begin{array}{l}2.89(0.98) \\
2.63^{\star}(1.01)\end{array}$ & $\begin{array}{l}3.86(0.67) \\
3.84(0.73)\end{array}$ & $3 \cdot 42$ & 0.02 \\
\hline \multicolumn{7}{|l|}{ Site 2: } \\
\hline $\begin{array}{l}\text { Initial } \\
\text { Follow up }\end{array}$ & $3 \cdot 12(1 \cdot 07)$ & $3.62(0.78)$ & $2 \cdot 85(1.09)$ & $3.85(0.80)$ & $<1$ & NS \\
\hline \multicolumn{7}{|c|}{$\begin{array}{l}\text { Satisfaction with amount of sleep } \\
\text { (1 = not enough, } 5=\text { plenty): } \\
\text { Site } 1 \text { : }\end{array}$} \\
\hline $\begin{array}{l}\text { Before change } \\
\text { After change }\end{array}$ & $\begin{array}{l}2 \cdot 74(1 \cdot 11) \\
3 \cdot 31^{\star}(0 \cdot 72)\end{array}$ & $\begin{array}{l}4.07(0.58) \\
3.63^{\star}(0 \cdot 88)\end{array}$ & $\begin{array}{l}3 \cdot 20(0 \cdot 90) \\
2 \cdot 83^{\star}(1 \cdot 15)\end{array}$ & $\begin{array}{l}4 \cdot 17(0.54) \\
4 \cdot 17(0.54)\end{array}$ & $14 \cdot 20$ & 0.001 \\
\hline \multicolumn{7}{|l|}{ Site 2: } \\
\hline $\begin{array}{l}\text { Initial } \\
\text { Follow up }\end{array}$ & $3.25(1.02)$ & $3 \cdot 88(0 \cdot 66)$ & $3 \cdot 10(1 \cdot 12)$ & $4.02(0.63)$ & $<1$ & NS \\
\hline \multicolumn{7}{|c|}{$\begin{array}{l}\text { Awaken refreshed from sleep } \\
(1=\text { not at all, } 5=\text { extremely }) \\
\text { Site } 1:\end{array}$} \\
\hline $\begin{array}{l}\text { Before change } \\
\text { After change }\end{array}$ & $\begin{array}{l}2 \cdot 65(1 \cdot 06) \\
3 \cdot 15^{\star}(0 \cdot 78)\end{array}$ & $\begin{array}{l}3.89(0 \cdot 69) \\
3 \cdot 60^{\star}(0 \cdot 78)\end{array}$ & $\begin{array}{l}2 \cdot 80(0.99) \\
2 \cdot 51^{\star}(0.96)\end{array}$ & $\begin{array}{l}4 \cdot 16(0 \cdot 71) \\
4 \cdot 07(0 \cdot 60)\end{array}$ & $10 \cdot 92$ & 0.001 \\
\hline \multicolumn{7}{|l|}{ Site $2:$} \\
\hline $\begin{array}{l}\text { Initial } \\
\text { Follow up }\end{array}$ & $\begin{array}{l}3.00(0.97) \\
2.95(0.96)\end{array}$ & $\begin{array}{l}3.66(0 \cdot 73) \\
3.61(0.81)\end{array}$ & $\begin{array}{l}2.79(1.06) \\
2 \cdot 70(1.00)\end{array}$ & $\begin{array}{l}3.93(0.79) \\
3.93(0.76)\end{array}$ & $1 \cdot 05$ & NS \\
\hline
\end{tabular}

$\star \mathrm{P}<0.05 v$ before change (Newman-Keuls test). $\mathrm{F}$ values are from the interaction of test phase with shift. 
in the diaries from initial to follow up testing were not consistent for the various measures. Consequently, it is difficult to attribute these differences to the work schedule.

No interactions between age group and test phase were found at either site for measures of sleep quality. Overall, however, older workers rated their night shift sleep as lower in quality than the younger group on the standard shiftwork index, as indicated by a significant interaction of age group with shift ( $\mathrm{df}=3,450$, $F=3.83, \quad \mathrm{P}<0.02$ ) and subsequent tests between means.

FATIGUE, ALERTNESS, AND PERFORMANCE DURING THE SHIFT

Fatigue and alertness ratings

Figure 3 shows the standard shiftwork index ratings of tiredness and visual analogue scale ratings of sleepiness at each worksite as a function of test phase for each shift. Both standard shiftwork index fatigue ratings and visual analogue sleepiness ratings from site 1 were lower for the morning shift, and higher for evening and night shifts, after the change to the new schedule. A similar pattern from initial to follow up testing was not apparent for either measure at site 2 .

Differences at each test phase for each shift at site 1 were supported by a significant interaction of test phase by shift for both the standard shiftwork index fatigue rating ( $\mathrm{df}=2$, $104, F=20.27, \mathrm{P}<0.001)$ and the visual analogue sleepiness rating $(\mathrm{df}=2,377, F=$ $3.54, \mathrm{P}<0.03)$. No significant interactions of shift with test phase were found at site 2 . Tests of means from site 1 showed a significant decrease from before to after the change in both tiredness and sleepiness during the morning shift. For evening shift, only the standard shiftwork index of tiredness was significantly different between tests before and after the change. For the night shift, only the visual analogue sleepiness rating was significantly different before and after the change.

No interaction between test phase and age group was found for standard shiftwork index ratings of tiredness or visual analogue ratings of sleepiness. However, overall differences in standard shiftwork index of tiredness were found between age groups as a function of shift. Older workers at both worksites rated their tiredness in the morning shift as lower than the younger group, as indicated by a significant interaction of age group with shift ( $\mathrm{df}$ $=2,192, F=9.89, \mathrm{P}<0.001)$ and subsequent tests between means.

Table 4 Percentage of missed signals in the choice reaction time task at each test phase as a function of time in shift at sites $1(n=20)$ and $2(n=25)$

\begin{tabular}{|c|c|c|}
\hline & \multicolumn{2}{|l|}{ Time in shift } \\
\hline & $\begin{array}{l}\text { Early } \\
\text { mean (SD) }\end{array}$ & $\begin{array}{l}\text { Late } \\
\text { mean (SD) }\end{array}$ \\
\hline $\begin{array}{l}\text { Site 1: } \\
\text { Before change } \\
\text { After change }\end{array}$ & $\begin{array}{l}0.13(0.53) \\
0.23(0.66)\end{array}$ & $\begin{array}{l}0 \cdot 03(0 \cdot 16) \\
0 \cdot 74^{\star}(2 \cdot 00)\end{array}$ \\
\hline $\begin{array}{l}\text { Site 2: } \\
\quad \text { Initial test } \\
\text { Follow up test }\end{array}$ & $\begin{array}{l}0.11(0.39) \\
0.12(0.37)\end{array}$ & $\begin{array}{l}0.31(2.57) \\
0.51(2.43)\end{array}$ \\
\hline
\end{tabular}

$\star \mathrm{P}<0.05 v$ early in shift (Newman-Keuls test).

\section{Performance}

Table 4 shows the percentage of missed signals in the choice reaction time task for each worksite. Misses became more frequent from early to late in the shift after the schedule change, as reflected in the significant interaction of test phase with time on shift $(\mathrm{df}=1$, $377, F=6.51, P<0.02)$. No differences in missed signals between the test phases were found at site 2 . Choice reaction time errors, however, were less frequent during follow up testing ( $\mathrm{df}=1,444, F=6.05, \mathrm{P}<0.02)$. This improvement was attributed to practice as the effect was not associated with specific aspects of the work schedule.

No interaction between test phase and age group was found for any measure in the reaction time task. Overall, however, older workers were slower to respond $(\mathrm{df}=1,40, F=$ $8.29, \mathrm{P}<0.007)$ and tended to make fewer errors $(\mathrm{df}=1,40, F=4.00, \mathrm{P}<0.06)$.

\section{OTHER VARIABLES}

The schedule change at site 1 resulted in increased morningness scores ( $\mathrm{df}=1,39, F$ $=5.14, P<0.03$ ), and ratings of more frequent interference of shiftwork with domestic activities $(\mathrm{df}=1,53, F=5.54, P<0.03)$ and other activities $(\mathrm{df}=1,53, F=5.66$, $P<0.03$ ). At site 2 , follow up testing resulted in ratings of more frequent interference of shiftwork with other activities (df $=1,98, F$ $=7 \cdot 13, \mathrm{P}<0.009)$. All other variables-for example, health complaints, job satisfaction, chronic fatigue, mental and physical workload-remained unchanged at follow up tests.

\section{Discussion}

The results of the present study suggest that as little as a one hour delay in shift starting times can improve sleep before the morning shift, and reduce sleepiness and improve waking fatigue during the morning shift. This conclusion was supported by increases in measures of total sleep time in the sleep diary and actigraph, a similar but non-significant increase in the standard shiftwork index measure of total sleep, improvements in standard shiftwork index measures of sleep quality and job related fatigue, and reductions in on site measures of subjective sleepiness (visual analogue scale). Similar changes in these measures did not occur at site 2 (no schedule change), which increases confidence that the results are attributable to the change in start and end times.

The present results also indicate that evening and night shift sleep and fatigue or sleepiness were affected negatively by the new work schedule, but those results were less consistent across all measures. For the evening shift, a decrease of sleep quantity and sleep quality and an increase in fatigue on the standard shiftwork index were found after the schedule change. The change in sleep quantity, however, was not supported by the diary or actigraph measures. Regardless of the measure, substantial sleep was still reported after the evening shift, as mean total sleep time was greater than $7 \cdot 0$ hours (within the normal 
seven to eight hour range for adult sleepers). Furthermore, fatigue and sleepiness ratings during the evening shift under the new work schedule remained at low levels in comparison with other shifts. For the night shift, sleep quality decreased on the standard shiftwork index, sleep quantity decreased in the diaries (but not in the standard shiftwork index or actigraph), and subjective sleepiness increased after the schedule change.

Other differences after the schedule change generally were negative but were not related to specific shifts. Sleep quality decreased in the diaries, and shiftwork interfered more with domestic and other personal activities. Also, missed signals in the reaction time task were more frequent after the schedule change. These misses reflect periodic lapses in alertness during which no attention is given to the appropriate stimuli. ${ }^{30}$ Consequently, decreased sleep quality coupled with poorer reaction time suggest an overall increase in sleepiness during the new schedule.

The results of the present study are consistent with previous studies reporting a positive correlation between morning shift starting time and quality and quantity of morning sleep and waking alertness. ${ }^{3-9}$ The advantages gained in morning shift, however, were offset somewhat by negative effects on evening and night shifts. For night shift especially, these effects warrant concern although the results were not robust or consistent across measures. They are cause for concern because night shift sleep quantity and quality were already at low levels, and night shift fatigue and sleepiness were at high levels, before the new work schedule.

The improvements associated with morning shift and the decrements associated with night shift under the new work schedule can be attributed both to circadian rhythm and social and domestic factors. Because of a high level of circadian arousal and the likelihood of social activities, it is often difficult to go to sleep early in the evening in preparation for waking early in the morning. ${ }^{312}$ Consequently, a late bedtime with an early rise results in reduced sleep and increased fatigue. A later morning starting time allows a later waking time which allows more sleep. The later ending time for the corresponding night shift, however, can limit daytime sleep because high circadian arousal makes it difficult to remain asleep in the afternoon. ${ }^{12}$ Late afternoon domestic and social activities can set additional limitations on daytime sleep, especially in those families with young children returning from school. ${ }^{31}$

Wide seasonal variations in the availability of daylight in Finland also might explain some of the differences between initial and follow up tests, but not those associated with sleep or fatigue. No consistent patterns in sleep or fatigue between worksites were found from the first to the second test phase. In both factories, however, standard shiftwork index ratings that the work schedule interfered with social or personal activities increased from the first questionnaire (spring) to the second question- naire (winter). As very little daylight is available in Finland during the winter months (sunset before 1600 in December), it is plausible that a morning shift ending at 1500 , or the work schedule in general, interferes with personal activities which depend on daylight. Such an interference would be most apparent in the winter months (the second test phase).

There were few age differences associated with the change of work schedule. The lack of substantial interactions with age suggests that the effects of the work schedule were uniform across age groups. This suggestion is plausible because the age difference between groups was not extreme (young $v$ middle age). The small number of workers in each age group, however, suggests the additional possibility that there was insufficient statistical power to detect interactions between the groups. However, the fact that we found overall differences between age groups, or significant interactions between age group and shift, indicates that our measures were sensitive to age within the context of evaluation of the work-rest schedule. Indeed, the age effects we found are consistent with previous studies of aging and sleep $^{151719}$ or aging and performance (for review see Salthouse ${ }^{32}$ ). Older people, for example, tend to sacrifice speed of response to maintain accuracy at levels which are equal, or superior, to the accuracy of younger people. Such a phenomenon was found in the choice reaction time task used in the present study.

In conclusion, it is notable that the new work schedule was not adopted permanently at the steel rolling mill as $75 \%$ of the workers voted against retention of the new schedule. Conversations with workers' representatives suggested that the new schedule was unpopular because it interfered with social and other personal activities. These opinions are consistent with our analysis of standard shiftwork index items about social and domestic activities. The increase in morningness scores, which indicate a preference for early waking, also might be a reflection of dislike for the later starting times. Whether poor sleep or fatigue contributed to the perception of interference, or the increase in morningness, will be the subject of a later report about individual differences in response to the work schedule change. Some preliminary analysis of the standard shiftwork index sleep variables along these lines, however, suggests that those who voted to retain the new schedule derived the most benefit in terms of improved sleep.

As a final note, the present study reinforces the notion that any worksite intervention carries both advantages and disadvantages, and that systematic evaluation of an intervention is necessary to elucidate these tradeoffs. The present evaluation of a change in morning shift starting and ending times showed positive outcomes in some psychophysiological variables, such as sleep and alertness, but also pointed to negative outcomes associated with social and personal factors. It seems, then, that optimal shift start and end times for an entire organisation would be difficult to institute on a wide scale. Perhaps the best possibility would be to 
establish several autonomous groups who can choose their own start and end times based on both job demands and personal issues. ${ }^{1}$ This type of system currently is being implemented at the steel rolling mill which was the subject of the present study.

1 Knauth P. The design of shift systems. Ergonomics 1993 36:15-28

2 Knauth P, Rutenfranz J. Development of criteria for the design of shiftwork systems. F Hum Ergol (Tokyo) 1982;11(suppl):337-67.

3 Folkard S, Barton J. Does the "forbidden zone" for sleep onset influence morning sleep duration? Ergonomics onset influence

4 Kecklund G, Åkerstedt, T. Effects of timing of shifts on sleepiness and sleep duration. Proceedings of a consensu conference on work hours, sleepiness, and accidents. Stockholm, Sweden: Karolinska Institute 1994:59-63.

5 Bjerner F, Holm $\AA$, Swensson $\AA$. Om natt- och skiftarber Statens Offentliga utredningar 1948:51. (In Swedish.)

6 Wallertz-Nilsson I. Sociala och psykologiska aspekter pa arbestidens forlaggning: en uppfoljningsstudie. Psykotekniska Institutet I Gotebors AB 1978. (In Swedish.)

7 Hak A, Kampman R. Working irregular hours: complaints and state of fitness of railway personnel. In: Reinberg A Vieux N, Andlauer P, eds. Night and shift work: biological and social aspects. Oxford: Pergamon Press, 1981:229-36.

8 and social aspects. Oxford: Pergamon Press, 1981:229-36. Knauth P, Landau K, Droge C, Schqitteck M, Widynski
M, Rutenfranz J. Duration of sleep depending on the type of shift work. Int Arch Occup Environ Health 1980; 46:167-77.

9 Moors SH. Learning from a system of seasonallydetermined flexibility: beginning work earlier increases tiredness as much as working longer days. In: Costa $\mathrm{G}$ Cesena G, Kogi K, Wedderburn A, eds Shiftwork. health, sleep, and performance. Frankfurt am Main: Verlag Peter Lang, 1990:310-5.

10 Foret J, Lantin G. The sleep of train drivers: an example of the effects of irregular work schedules on sleep. In:
Colquhoun WP, ed. Aspects of human efficiency: diurnal Colquhoun WP, ed. Aspects of human efficiency: diurnal
rhythm and loss of sleep. London: English Universities rhythm and loss of sleep. Lo

11 Czeisler CA, Weitzman ED, Moore-Ede MC, Zimmerman JC, Kronauer RS. Human sleep: its duration and organization depend on its circadian phase. Science 1980 210:1264-7.

12 Åkerstedt T, Folkard S. Sleep onset and offset prediction using the three-process model of alertness regulation. $\mathcal{F}$ Sleep Res 1993;3(suppl):4.

13 Ishihara K, Miyake S, Miyasita A, Miyata Y. Morningnesseveningness preference and sleep habits in Japanese office eveningness preference and sleep habits in Japanese office
workers of different ages. Chronobiologia 1992;19:9-16.

14 Monk TH, Reynolds CF, Buysse DJ, Hoch CC, Jarret DB, Jennings JR, Kupfer DJ. Circadian characteristics of healthy 80 -year-olds and their relationship to objectively recorded sleep. f Gerontology 1991;46:M171-5.

15 Torsvall L, Ákerstedt F, Gillberg M. Age, sleep and irregular work hours. A field study with electroencephalographic recordings, catecholamine excretion and graphic recordings, catecholamine excretion and self-ratings.

16 Foret J, Bensimon G, Benoit O, Vieux N. Quality of sleep as a function of age and shift work. In: Reinberg A, Vieux N, Andlauer P, eds. Night and shift work. Biological and social aspects. Oxford: Pergamon Press, 1981.

17 Härmä M, Hakola T, Laitinen J. Relation of age to circadian adjustment to night work. Scand $\mathcal{f}$ Work Environ Health 1992;18(suppl 2):116-8.

18 Walsh JK, Schweitzer PK. Laboratory studies of transient insomnia, shift-work and jet lag: effects on sleep and sleepiness. In: Horne J, ed. Sleep '88. Stuttgart: Gustav sleepiness. In: Horne J, ed.

19 Pavard B, Vladis A, Foret J, Wisner A. Age and long term shiftwork with mental load: their effects on sleep. $\mathcal{F}$ Hum Ergol (Tokyo) 1982;11(suppl):303-9.

20 Folkard S, Barton J, Costa G, Smith L, Spelten E, Totterdell P. The standard shiftwork index. Ergonomics 1993;36:313.

21 Rosa RR, Bonnet MH. Performance and alertness on 8hour and 12-hour rotating shifts at a natural gas utility. Ergonomics 1993;36:1177-93.

22 Rosa RR. Performance, alertness, and sleep after 3.5 years of 12-hour shifts: a follow-up study. Work Stress 1991;5: 107-16.

23 Rosa RR, Colligan MJ, Lewis P. Extended workdays: effects of 8-hour and 12-hour rotating shift schedules on performance, subjective alertness, sleep patterns, and psychosocial variables. Work Stress 1989;3:21-32.

24 Härmä M, Suvanto S, Partinen M, Ilmarinen J. The effect of 4-day round flight over 10 time zones on the sleep-wakefulness of flight attendants. Ergonomics 1994;37:1479-89.

25 Rosa RR, Colligan MJ. Long workdays $v$ restdays: assessing fatigue and alertness with a portable performance battery. Hum Factors 1988;30:305-17.

26 Rosa RR, Wheeler DD, Warm JS, Colligan MJ. Extended workdays: effects on performance and ratings of fatigue and alertness. Behavioural Research Methods, Instruments and Computers Computers 1985;17:6-15.

27 Myers JL. Fundamentals of experimental design. Boston Myers JL. Fundamentals
Allyn and Bacon, 1979.

28 SAS Institute. SAS/STAT user's guide, release 6.03. Cary, NC: SAS Institute, 1988.

29 SAS Institute. Technical report P-229 SAS/STAT software: changes and enhancements, release 6.07. Cary, NC: SAS Institute, 1992.

30 Bills AC. Blocking: a new principle in mental fatigue. $A m \mathcal{F}$ Psycholo 1931;43:230-45.

31 Colligan MJ, Rosa RR. Shiftwork effects on family and social life. In: Scott A, ed. Occupational medicine state of the art reviews, vol 5: shiftwork. Philadelphia: Hanley the art reviews, vol

32 Salthouse, TA. Influence of experience on age differences in cognitive functioning. Hum Factors 1990;32:551-70.

\section{Rejected manuscripts}

From February 1994, authors whose submitted articles are rejected will be advised of the decision and one copy of the article, together with any reviewers' comments, will be returned to them. The fournal will destroy remaining copies of the article but correspondence and reviewers' comments will be kept. 